\title{
The role of annealing temperature on the optical energy gap and Urbach energy of Se:2\% Sb thin films
}

\author{
A.F. Abdul-Ameer*
}

Date of acceptance 25/3/2008

\begin{abstract}
:
The optical energy gap $\left(E_{\text {opt }}\right)$ and the width of the tails of localized states in the band gap $(\Delta \mathrm{E})$ for $\mathrm{Se}: 2 \% \mathrm{Sb}$ thin films prepared by thermal co-evaporation method as a function of annealing temperature are studied in the photon energy range ( 1 to 5.4$) \mathrm{eV}$.Se $2 \% \mathrm{Sb}$ film was found to be indirect transition with energy gap of $(1.973,2.077,2.096,2.17) \mathrm{eV}$ at annealing temperature $(295,370,445,520) \mathrm{K}$ respectively.

The $\mathrm{E}_{\mathrm{opt}}$ and $\Delta \mathrm{E}$ of $\mathrm{Se}: 2 \% \mathrm{Sb}$ films as a function of annealing temperature showed an increase in $\mathrm{E}_{\mathrm{opt}}$ and a decrease in $\Delta \mathrm{E}$ with increasing the annealing temperature. This behavior may be related to structural defects and dangling bonds.
\end{abstract}

\section{Introduction:}

Optical properties of thin films depend mainly on their volume and surface structures[1-2].Film structure is affected by its thickness, conditions of preparation, films material,substrate bulk material and its treatment after preparation [3-5].In recent years, the optical memory effects in amorphous semiconducting films have been investigated and utilized for various device applications[6].

The optical absorption coefficient for many amorphous and glassy materials is found to obey the relation:

$$
\alpha h v=\beta(\text { hv-Eopt })^{r}
$$

where $v$ is the frequency of the incident radiation, $\beta$ is a constant which depends on density of state of conduction and valence bands, $r$ is a constant depend on the nature of the transition and Eopt is the optical energy gap.

The relation was first derived by Tauc and Colleagues[1] who assumed that the electron density of states at band edges in regions of localized states is a parabolic function of energy .Davis and Mott[7] obtained the same relation. The width of the tails of localized states at the band edges can be estimated using the Urbach relation[8]: $\alpha=\alpha_{0} \exp (\mathrm{h} v / \Delta \mathrm{E})$

where $\alpha_{0}$ is a constant and $\Delta \mathrm{E}$ is a measure of the extent of the band tailing in the band gap of the material and determined from the reciprocal of the slope of $\ln \alpha$ against photon energy.

This report will give results of a systematic study of the optical properties of $\mathrm{Se}: 2 \% \mathrm{Sb}$ amorphous thin films at different annealing temperature $(295,370,445 \& 520) \mathrm{K}$.

\section{Experiment:}

The purity of the materials are (99.999\% pure), were prepared at room temperature by thermal co-evaporation technique from two molybdenum boats in a vacuum at a pressure of $\operatorname{about}\left(5 \times 10^{-6}\right.$ )Torr using Edwards 306 coating unit.The thickness of films was $(\sim 300 \pm 5) \mathrm{nm}$ measured using Tolonsky methods.

The glassy nature of the samples were investigated using X-Ray diffraction. Spectral characteristics in the wavelength rang (200-1100)nm were measured using UV-visible recording spectrophotometer(UV-160 Schematize). The absorption coefficient $(\alpha)$ calculated from the relation [9]:

\footnotetext{
*Department of Physics ,College of Science, University of Baghdad , Jadirya-Baghdad-IRAQ
} 
$\alpha=2 \cdot 303(\mathrm{~A} / \mathrm{t})$

where $\mathrm{A}$ is the absorbance and $\mathrm{t}$ is the thickness of the films. The optical band gap calculated from the intercept of $(\alpha h v)^{1 / 2}$ data plotted as function of photon energy.

\section{Results and discussions:}

The films samples unannealed and annealed at various temperature were amorphous which are conformed by X-ray diffraction as shown in fig. (1). Fig.(2) shows the plots of absorption coefficient $(\alpha)$ versus photon energy (hv) at different annealing temperature. As evident from Fig.(2), $\alpha$ varies exponentially with hv in the measured range of $\alpha$. The absorption edge at room temperature is in a good agreement with the result on $\mathrm{Se}: 2 \% \mathrm{Sb}$ glass reported by Al-Ani et.al.[10,11].Fig.(3) show plots $(\alpha h v)^{1 / 2}$ against photon energy of Se:2\% Sb films deposit at room temperature and annealed to $(370,445,520) K$. Fig.(4) shows the plot of $\ln \alpha$ against photon energy of $\mathrm{Se}: 2 \% \mathrm{Sb}$ films deposited at room temperature. The reciprocal of the slope of curve give the value of corresponding $\Delta \mathrm{E}$ $(0.45,0.38,0.29,0.23) \mathrm{eV}$ at annealing temperature

$(295,370,445.520) \mathrm{K}$ respectively The extrapolated value of the indirect energy gap were $(1.973,2.077,2.096,2.17) \mathrm{eV}$ at annealing temperature of $(295,370,445,520) \mathrm{K}$ respectively as shown in Fig.(5) which is shows the variation of $\mathrm{E}_{\mathrm{opt}}$ and $\Delta \mathrm{E}$ with $\mathrm{T}$. The value of energy gap at room temperature is in agreement with Nang et.al.[12] but it's disagree with Choudhuri et. al.[13] which they found that the optical energy gap decrease with heat treatment.

The increasing in annealing temperature changes the density of localized state to a lower values as well as the localized state near the edges. Band gap at high temperature may be related to a decrease the structure defects such as dangling bonds, voids and decrease the disorder of the atomic bonds. The band tailing is a function of structural defects, therefor it decrease with increasing the annealing temperature as shown in Fig.(5).

\section{Conclusion:}

The optical transmission of $\mathrm{Se}: 2 \% \mathrm{Sb}$ films with thicknesses of $300 \mathrm{~nm}$ have been measured in order to drive data on the absorption edge and band tailing . They found to be a indirect energy gap. The $\mathrm{E}_{\text {opt }}$ for $\mathrm{Se}: 2 \% \mathrm{Sb}$ films showed an increase from a value of $1.978 \mathrm{eV}$ at room temperature to $2.17 \mathrm{eV}$ at $520 \mathrm{~K}$. While $\Delta \mathrm{E}$ showed to be decreases with increasing the annealing temperature. These results may be related to a decrease in voids and dangling bonds.
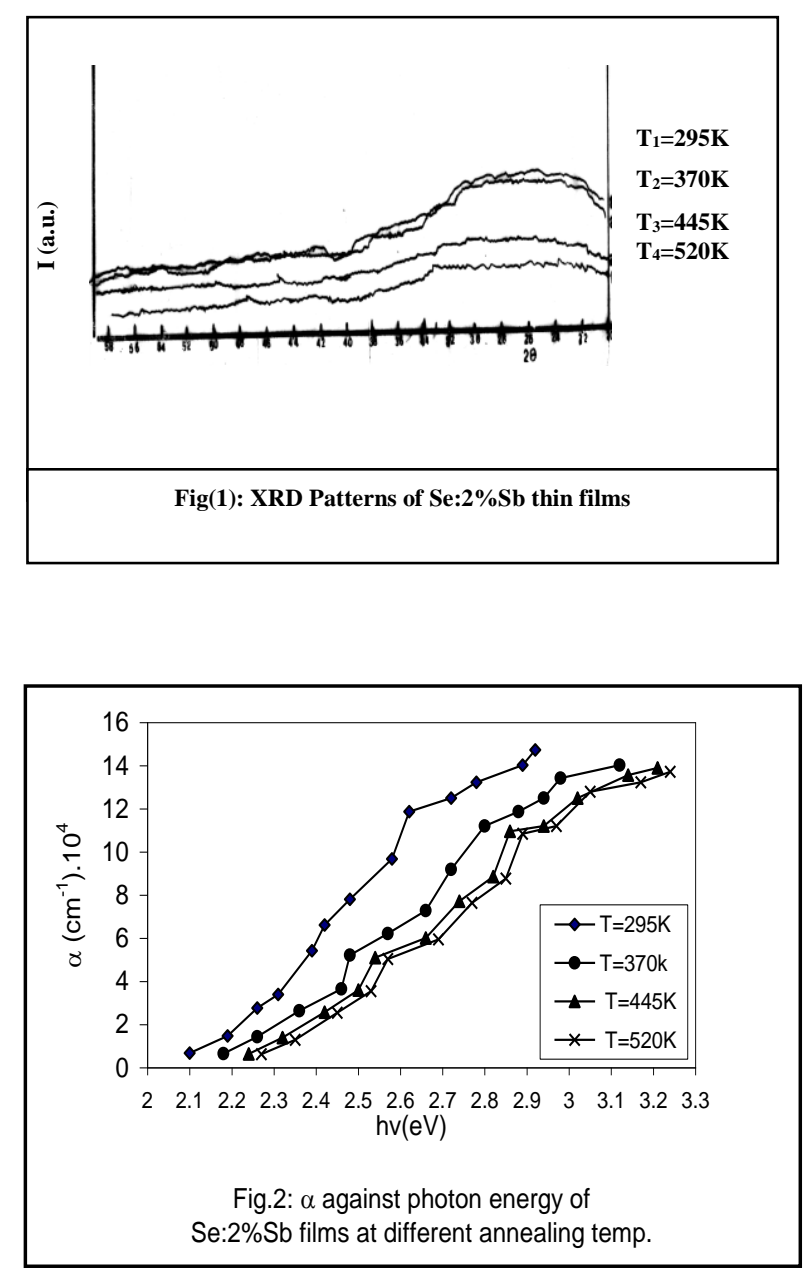

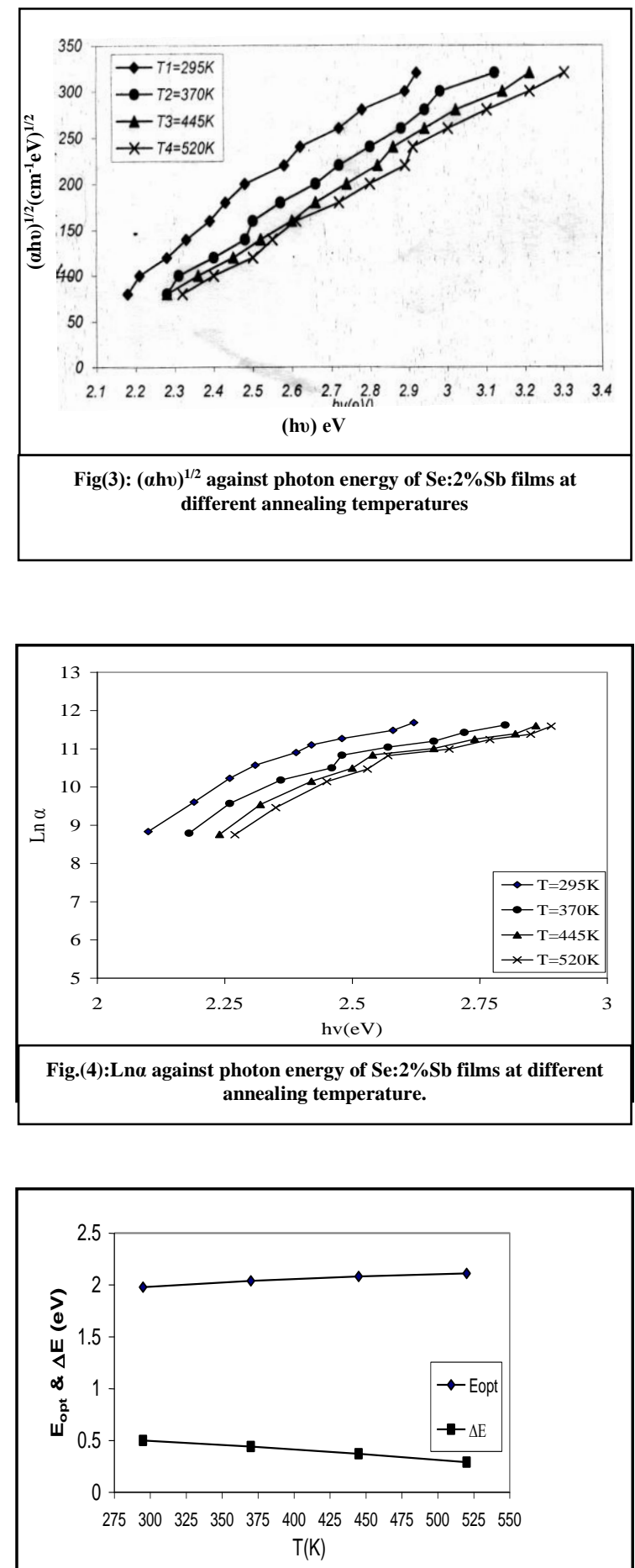

Fig.(5):Variation of Eopt and $\Delta \mathrm{E}$ against annealing temperatures of $\mathrm{Se}: 2 \% \mathrm{Sb}$ films.

\section{References:}

1. Saad, M.M., A.A.Saad,A.M.Elhelou, S.M.Botors, 1988,Optical properties of selenium thin films, OpticaApplicata. 17(2):.105.
2. Al-Ani, S.K.,M.N.Makadsi, N.K. Abass.,2005,"Structural studies of the Ge-Se-Bisystem"J.of Natural and Applied Sciences, 9(2):399.

3. Abbas, L.K.,2003, The study of the effect of annealingtemperature onthe optical properties of Ge-Se semicond. ,J.ofCollege of Education, 12(2):372.

4. Chadhi,S.,S.Biswas, 1981, Amorphous to crystallian Transition of selenium thin films of different thickness, JNon- Cryst. Solid, 4(171) : 171.

5. Twaddeii,V.A.,W.C.Lacourse., andJ.D .Mackenzie,1972,"Impurity effects on the structure and electrical properties of non-crystalline selenium"J.of Noncrystalline Solids, 8(10):p.189.

6. Khan,Z.H.,M.Zulfeqaur,andM.Husain, 2002,Electricalconductivity and thermoelectric power of a-Se $e_{80-\mathrm{x}} \mathrm{In}_{\mathrm{x}}$ and $\mathrm{Se}_{80-\mathrm{x}} \mathrm{Ge}_{20} \mathrm{In}_{\mathrm{x}}$ thin films."Canda $\mathrm{J}$. Phys. 10.

7. Davis, E., N.Mott,1979,Electronic process in Non-crystallian materials $2^{\text {nd }}$ ed.,Claredon Press.Oxford.

8. Ihm J.,1985,.Urbach tails and the structure of chalcogenide Glasses. 53(3):293.

9. Jenkins, F.,H. White, 1957,. Fundamentals of optics., $3^{\text {rd }}$ ed.,Mc Graws-Hill Book Company,New York.

10. Al-Ani,S.KM.N. Makadsi,L.K. Abbas, 1999, The effect of some additives on optical properties of a-Se thin films,Second Scientific Conference/ College of Scince/University of Baghdad.

11. Al-Ani,S.K.J., 1984,.Studiesof Optical and related Properties ofThin Amorphuos film. Ph.D.Thesis, Brunel University, England.

12. Nang,T.T.,M. OkudaM.,1979, Cmpositionnn dependenc of the rrefractive index and its photon energy variation in the system e-Se andAs-Se,J.of Non Cryst. Solid,33 (311):311-322. 
13. Chaudhuri ,S.,S. Biswas, 1983, selenium film on heat treatment,J.NonVariation of optical ofamorphous Cryst.Solids, 54:179-182.

Se:2\%Sb تأثير درجة حرارة التلدين على فجوة الطاقة البصرية وطاقة اورباخ لأغثية أمير فيصل عبل الأمير* * جامعة بغداد/كلية العلوم/قسم الفيزياء

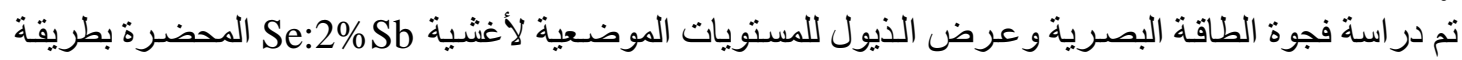

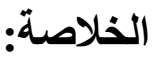

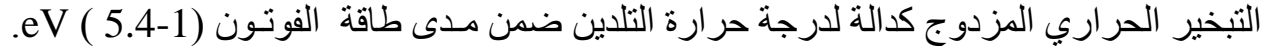

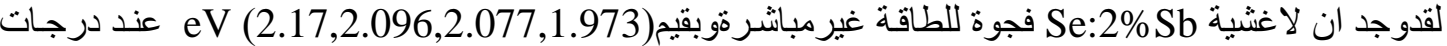

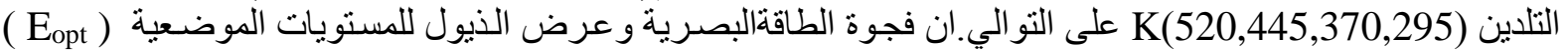

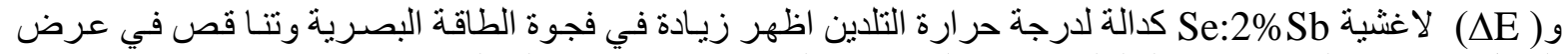

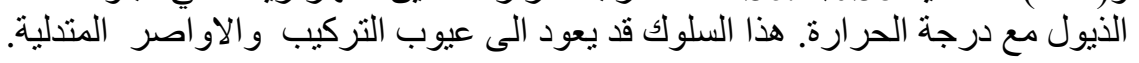

